\title{
REVISÃO E DISCUSSÃO DO SIGNIFICADO TECTÔNICO DE GRANITÓIDES DO TIPO-S NEOPROTEROZÓICOS NO ESTADO DO RIO DE JANEIRO
}

\author{
RÔMULO MACHADO ${ }^{1} \&$ NOLAN MAIA DEHLER ${ }^{2}$
}

\begin{abstract}
REVIEW AND DISCUSSION ABOUTTHE TECTONIC MEANING OF NEOPROTEROZOIC S-TYPE GRANITOIDS IN THE STATE OF RIO DE JANEIRO The S-type granitoids, described as syncollisional in the literature, are now interpretated as late collisional. The generation of these granitoids is related to the partial melting (anatexis) of metasedimentary rocks. Their emplacement was controled by ductile shear zones of low- to high-angle. Peraluminous leucogranites with garnet, muscovite, sillimanite and turmaline predominante. They are foliated and gneissified, and have granitic and granodioritic composition. The enclaves are metasedimentary rocks (calci-silicatic, quartzite, garnet-biotite gneiss). Two tectonic models are discussed for the generation these rocks: one with initial crustal duplication (Alpine-Hymalaian type) and other without significative crustal thickening. The first model is in accord with different tectonic models proposed for the belt. In this model, the peak of metamorphim is reach after compressional tectonic and crustal thickening, for a range of normal physical parameters in the crust, with metamorphic conditions corresponding to the amphibolite and granulite facies. The syncollisional anatexis occurs more easily when the pre-collisional crust is relatively hot and/or satured in water. The second model involve the injection of magma and/or partial melting in the base of crust. The solid state deformation in these rocks may be interpreted by reativation of regional shear zones or as progressive superposition of structures related of orogenic exhumation at the end Brasiliano Cycle.
\end{abstract}

Keywords: S-type granitoids, late collisional, crustal anatexis

Resumo Granitóides do tipo-S, descritos anteriormente como sin-colisionais, são aqui interpretados como tardi-colisionais, sendo considerados portanto como tardios ao espessamento tectônico da fase colisional. A geração destas granitóides é relacionada à fusão parcial (anatexia) de rochas dominantemente metassedimentares e a sua colocação foi controlada por zonas de cisalhamento dúcteis de baixo a alto ângulo. São leucogranitos peraluminosos (granada, moscovita, sillimanita e turmalina), foliados e gnaissificados, de composição granítica a granodiorítica, ricos em enclaves metassedimentares (calcissilicáticas, quartzitos, granada-biotita gnaisses). Dois modelos tectônicos são discutidos para a geração destas rochas: um modelo envolvendo duplicação crustal inicial (tipo Alpino-Himalaiano) e outro sem espessamento crustal significativo. O primeiro modelo é compatível com os modelos tectônicos existentes na literatura para este segmento do cinturão. Neste modelo, o ápice térmico é alcançado após a tectônica compressiva e a duplicação crustal, num intervalo de parâmetros físicos normais, sob condições metamórficas compatíveis com as fácies anfibolito alto a granulito. A anatexia sin-colisional ocorre mais facilmente na presença de uma crosta relativamente quente e/ou sob condições de saturação em água. O segundo modelo envolve a injeção de magma e/ou fusão parcial na base da crosta, com a transferência de calor para a crosta média sendo promovida pela ascensão de magmas. As condições de $\mathrm{P}$ e T compatíveis para fusão parcial extensiva ocorrem logo após ao ápice do espessamento crustal, pois durante esta fase (fase sin-colisional) as fusões expressivas são condicionadas pela disponibilidade de água no sistema ou pela existência de uma crosta anormalmente quente. A deformação em estado sólido imposta à estas rochas pode ser explicada pela reativação das zonas de cisalhamento regionais ou pela superposição contínua de estruturas durante a exumação do orógeno no final do Ciclo Brasiliano.

Palavras-chaves: granitóides tipo-S, tardi-colisional, anatexia crustal.

INTRODUÇÃO A cartografia geológica do estado do Rio de Janeiro na escala de semi-detalhe (1:50.000) foi empreendida no final da década de 70 e início da década de 80 , sob a coordenação do DRM-RJ (Departamento de Recursos Minerais do Estado do Rio de Janeiro), onde participaram diversas empresas privadas (GEOSOL, TRISERVICE e GEOMITEC) e do governo(CPRM - O Serviço Geológico do Brasil), incluindo as universidades federais (UFRJ, UFRRJ). Neste período, foram definidas as principais unidades geológicas pré-cambrianas do estado do Rio de Janeiro e sua respectivas nomenclaturas, cujos resultados encontram-se disponíveis sobretudo na forma de relatórios internos, juntamente com mapas e anexos diversos.

É desta época a edição do primeiro mapa geológico do estado do Rio de Janeiro pelo DRM em escala 1:400.000, o qual em linhas gerais reproduz as unidades geológicas maiores do mapa geológico de Rosier (1957). Posteriormente, Fonseca et al. (1998) publicaram um segundo mapa geológico do estado nesta mesma escala, incorporando nele as informações cartográficas derivadas dos trabalhos anteriores. Recentemente, a CPRM, após realizar a integração cartográfica da região em escala 1:250.000 (Folhas Volta

l - Instituto de Geociências da Universidade de São Paulo. Rua do Lago 562, Cidade Universitária, São Paulo. CEP: 05508-080. e-mail: rmachado@ @usp.br

2 - CPRM- Serviço Geológico do Brasil -SUREG-SP. e-mail: nolan@zipmail.com 
Redonda e Rio de Janeiro), apresentou um terceiro mapa do estado na mesma escala dos anteriores, onde destaca a presença de extensos corpos batolíticos de granitóides do tipo-S, anteriormente considerados como unidades de gnaisses diversos. A região de ocorrência destas rochas era restrita até então à porção sudoeste do estado do Rio de Janeiro, onde os trabalhos de cartografia geológica realizados pela GEOSOL e CPRM haviam definido respectivamente os maciços graníticos Serra das Araras e Rio Turvo (Barbosa \& Sad 1983, Ruiz et al. 1983).

Posteriormente, Machado \& Demange (1994), em trabalho de síntese regional sobre os granitóides do estado do Rio de Janeiro, denominaram estas rochas de granitos tipo-S e as consideram como sin-colisionais.

A partir do início da década dé 90 foram iniciados pela UERJ (Universidade Estadual do Rio de Janeiro) trabalhos de levantamento geológico nas regiões do vale do Paraíba do Sul e Serra dos Órgãos, que têm resultado na publicação de artigos e teses (Heilbron 1993 e 1995, Valladares 1996, Tupinambá 1999, Almeida 2000).

Este trabalho apresenta uma avaliação dos granitóides do tipo$\mathrm{S}$ do estado do Rio de Janeiro, juntamente com uma discussão sobre os modelos tectono/metamórficos disponíveis na literatura sobre a origem destas rochas. Incluiu-se também uma síntese dos granitóides neoproterozóicos do estado e uma revisão dos trabalhos de cartografia geológica realizados até então.

TRABALHOS ANTERIORES Poucos são os trabalhos de sínteses regionais disponíveis sobre as rochas granitóides neoproterozóicas do cinturão Paraíba do Sul no Estado do Rio de Janeiro (Machado \& Peloggia 1987, Machado \& Demange 1994, 1998, Machado 1997). Assinalam-se ainda sínteses parciais sobre os granitos tardi- a pós-tectônicos (Machado Filho et al. 1983, Junho \& Wiedemann 1987, Junho et al. 1987, Junho, 1991 e 1993, Leonardos Jr. 1973, Penha 1984, Penha \& Wiedemann 1984, Pires et al. 1982, Wiedemann et al. 1987b, Wiedemann 1993) ou ainda trabalhos incorporando também granitóides foliados (Heilbron 1995). Um grande volume de trabalhos são encontrados sobre maciços isolados, principalmente nos arredores da cidade do Rio de Janeiro e na região serrana de Petrópolis e Teresópolis (Puget \& Penha 1980, Junho \& Penha 1985, Chaves \& Pires 1986, Caddah et al. 1987, Rego 1989, Valente et al. 1991, Porto et al. 1992 e 1996, Machado \& Demange 1984, Hippertt 1990, Heilbron et al. 1992, Barbosa \& Sad 1995, Sanchez et al. 1995, Valladares 1996, Junho 1991, 1993, 1998, Tupinambá 1999). Estes trabalhos abordam sobretudo os aspectos petrográficos, litogeoquímicos e, mais raramente, geocronológicos, estruturais e de química mineral.

Almeida et al. (1993), ao realizarem mapeamento geológico na região de Barra Mansa, na divisa do Rio de Janeiro com São Paulo, assinalaram a existência de maciços graníticos foliados, contemporâneos com a fase principal de deformação ( $\sin -\mathrm{Dn}$ ), por eles denominados de Resgate, Campinho e Taquaral. Cabe mencionar, entretanto, que esta última denominação foi empregada para englobar o já então definido maciço Floriano, de Machado \& Peloggia (1987), e uma parte do granitóide Rio Turvo, definido por Ruiz et al. (1983).

Os dados geocronológicos ( $\mathrm{Rb} / \mathrm{Sr}$ e U/Pb) existentes sobre este magmatismo apontam idades no intervalo de 490 a $634 \mathrm{Ma}$ (Figueiredo \& Campos Neto 1993, Cordani et al. 1973, Machado N. et al. 1996, Machado R. et al. 1996, Machado 1997, Tupinambá 1999). Estes dados têm permitido dividir os granitos em pré-, sin e pós-colisionais, com intervalos respectivamente entre 590 a 570
Ma, 560 a $530 \mathrm{Ma}$, e a 520 a $480 \mathrm{Ma}$ (ou $450 \mathrm{Ma}$ ) (Figueiredo \& Campos Neto 1993, Wiedemann 1993, Heibron et al. 1995). São ainda propostos intervalos mais antigos: 650 a 620 (pré-colisional), 600 a $590 / 560 \mathrm{Ma}$ (sin-colisional) e 560 a $530 \mathrm{Ma}$ (tardi-colisional) (Machado 1997). No intervalo mais novo (entre 590 a $480 \mathrm{Ma}$ ) insere-se o Arco magmático Rio Doce) (Figueiredo e Campos Neto 1993, Campos Neto e Figueiredo 1995), enquanto no intervalo mais antigo (entre $590 \mathrm{Ma}$ a 620 ou $650 \mathrm{Ma}$ ) insere-se o Arco magmático Paraíba do Sul (Machado \& Demange 1998). Cabe salientar que a caracterização destes intervalos é bastante precária, pois a sua definição é baseada principalmente em idades $\mathrm{Rb} / \mathrm{Sr}$, não havendo ainda um acervo de dados geocronológicos suficientes, de alto valor interpretativo (U/Pb), que suportem os intervalos acima propostos.

Campos Neto \& Figueiredo (1995) propuseram para a região dois sistemas orogênicos superpostos: um mais antigo (entre 700 e $600 \mathrm{Ma}$ ), denominado Orogênese "Brasiliana I", e outro, mais novo (entre 590 e $480 \mathrm{Ma}$ ), denominado Orogênese Rio Doce. O primeiro sistema orogênico teria gerado cinturões de dobramento na borda sudeste do Cráton do São Francisco e acresção de distintas microplacas, com seu estágio pós-orogênico sendo bem marcado pela intrusão de granitos do tipo Rapakivi na Microplaca Apiaí-Guaxupé, há cerca de $600 \mathrm{Ma}$ atrás. O segundo sistema orogênico é melhor caracterizado na Microplaca Serra do Mar, com seu estágio pré-colisional sendo considerado no intervalo de 590 a $570 \mathrm{Ma}$.

\section{CARACTERÍSTICASEDISTRIBUIÇÃODOSGRANITÓIDES}

O mapa da figura 1 mostra a distribuição das rochas granitóides neoproterozóicas do Cinturão Paraíba do Sul no Estado do Rio de Janeiro. Estes granitóides são divididos em três grupos principais: (i) pré- a sin-colisionais, (ii) tardi-colisionais e (iii) pós-colisionais.

Os granitos pré- a sin-colisionais caracterizam-se por extensos batólitos lineares de granitóides do tipo-I, foliados, concordantes com as estruturas regionais. Correspondem a um magmatismo de composição expandida (granito/granodiorito/tonalito) com características petrográficas e geoquímicas comparáveis a dos batólitos do tipo- I Cordilherano (Machado \& Demange 1984a, 1998, Machado 1997). Estes granitóides, no domínio Litorâneo, estão associados com charnockitos ou rochas da associação charnockítica.

Os granitos tardi-colisionais ocorrem nos domínios Paraíba (Norte e Sul) e Litorâneo (Norte). Tais granitos, em ambos os domínios, estão estritamente ligados às zonas de cisalhamento de alto ângulo (Fig. 1). São distinguidos dois grupos principais de granitos: um de granitos do tipo- I, e outro de granitos do tipo- S. No primeiro grupo, que ocupa principalmente o domínio do Paraíba, destacamse os maciços Arrozal, Getulândia, Resende, Vassouras, Varre-Sai, Parati, dentre outros. Caracterizam-se por maciços alongados, foliados (foliação de fluxo magmático de alto ângulo), concordantes com as estruturas das rochas encaixantes. São inequigranulares e porfiríticos, rosados e esbranquiçados, de composição dominante monzogranítica. Contém enclaves microgranulares dioríticos a quartzo-dioritos que podem atingir extensão $\mathrm{Km}$, a exemplo do que ocorre no maciço Getulândia (Machado \& Demange 1994a). A biotita é o máfico dominante nesses granitos, ocorrendo também anfibólio (Parati e Varre-Sai). São disponíveis apenas duas idades $\mathrm{U} / \mathrm{Pb}$ em monazita para o maciço Getulândia, com valores de $528 \pm$ 1 Ma e $535 \pm 1 \mathrm{Ma}$ (Valladares 1996).

O segundo grupo de granitos ocupa os domínios Paraíba do Sul e Litorâneo Norte. No domínio Paraíba do Sul, os granitos acham- 


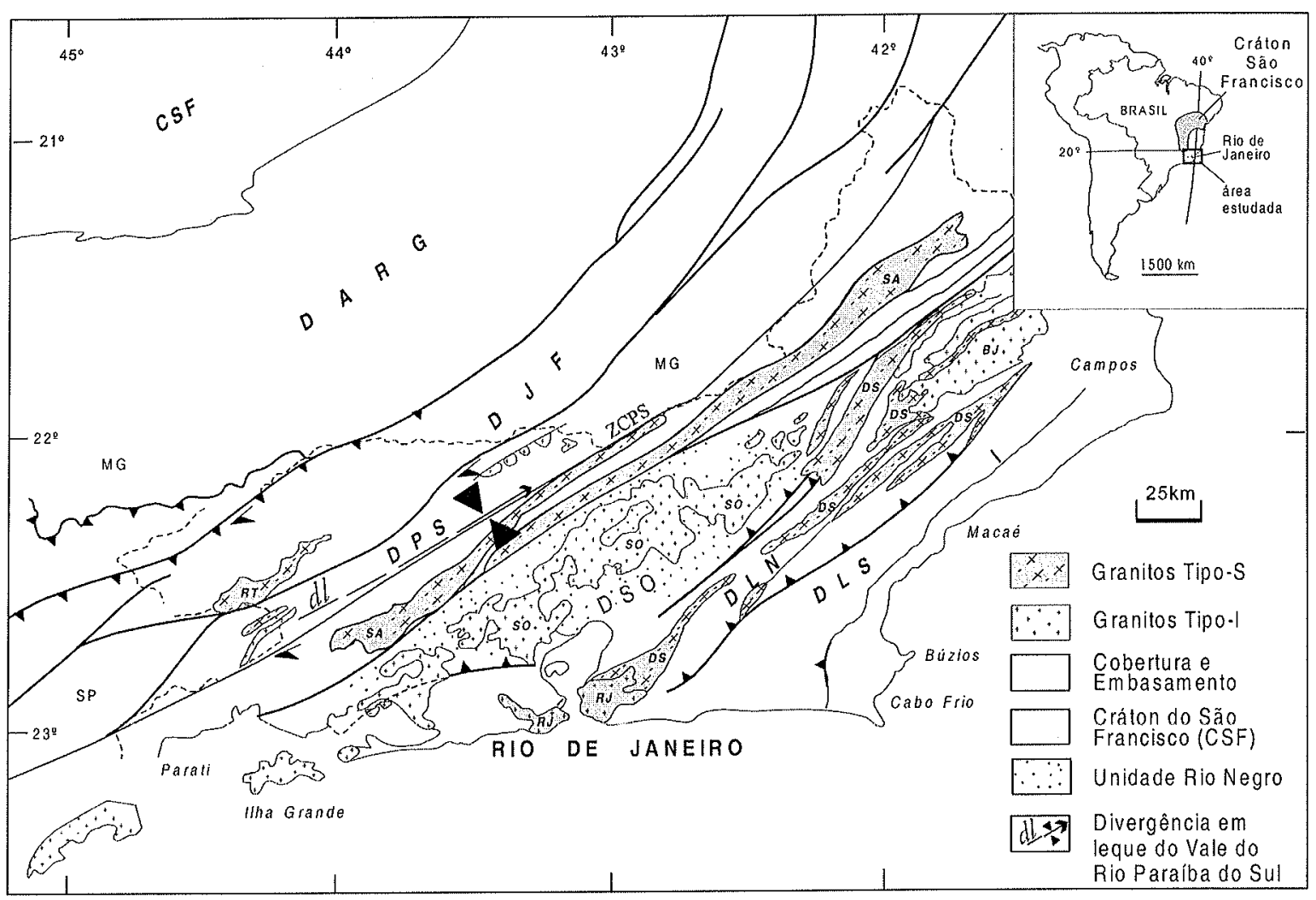

Figura 1 - Mapa de distribuição dos principais granitóides dos tipos-S e -I do Estado do Rio de Janeiro. Suítes graníticas do tipoS: Rio Turvo (RT), Serra das Araras (SA), Rio de Janeiro (RJ) e Desengano (DS). Batólitos graníticos do tipo- I: Serra dos Órgãos (SO) e Bela Joana (BJ). Domínios Alto Rio Grande (DARG), Juiz de Fora (DJF), Paraíba do Sul (DPS); Serra dos Órgãos (DSO) e Litorâneo Norte (DLN) e Sul (DLS); Cráton São Francisco (CSF); Zona de Cisalhamento Paraíba do Sul (ZCPS); VR- Volta Redonda; TR-Três Rios e PT-Petrópolis (Modificado de Machado \& Demange 1994 b e Silva et al. 2000).

se representado pelas Suítes Serra das Araras e Rio Turvo e no domínio Litorâneo Norte, pelas Suítes Desengano e Rio de Janeiro (Fig. 1). São maciços foliados, com aspecto migmatítico, dominados por leucogranitos de composição granítica a granodiorítica, ricos em enclaves submicáceos, contendo em sua mineralogia moscovita, granada, turmalina e sillimanita. São descritos, ainda, na região de Passa Três, leucogranitos com moscovita, granada e turmalina (Machado \& Demange 1994 a), que podem representar continuidade do batólito Serra das Araras.

Os granitos pós-colisionais ocorrem principalmente na parte sul dos domínios Litorâneo e Serra dos Órgãos (Fig. 1). A distribuição $\mathrm{E}-\mathrm{W}$ dos maciços sugere uma desvinculação das estruturas NE do cinturão durante a colocação dos mesmos. Alguns autores têm relacionado esta colocação a uma tectônica extensional (Machado 1997). Estes granitos são textural e composicionalmente semelhantes aos anteriores. Diferem, entretanto, pela geometria subarredondada em mapa, nível mais raso de colocação e contatos bruscos com as encaixantes. Estruturas de fluxo são restritas às bordas dos maciços. Ocorrem minerais de alteração como moscovita, clorita, carbonatos e minerais do grupo do epidoto. A fluorita aparece como mineral acessório em alguns maciços (São José do Ribeirão e Suruí). Os dados isotópicos $\mathrm{U} / \mathrm{Pb}$ e $\mathrm{Rb} / \mathrm{Sr}$ disponíveis são coerentes e apontam idades de $492 \pm 11 \mathrm{Ma}$ (U/ $\mathrm{Pb}$, em titanita) e $488 \pm 3,6 \mathrm{Ma}(\mathrm{Rb} / \mathrm{Sr}$, rocha total) respectivamente para os maciços Mangaratiba e Sana (Valladares 1996, Machado
1997). Uma idade $\mathrm{Rb} / \mathrm{Sr}$ de $501 \pm 20 \mathrm{Ma}$ foi obtida na fácies porfirítica do maciço Nova Friburgo (Tupinambá 1999).

Granitóides do tipo-S DOMÍMIO PARAÍBA DO SUL (DPS) Neste domínio, os granitóides do tipo- $\mathrm{S}$ foram reunidos nos trabalhos de cartografia geológica realizados pela GEOSOL e CPRM em escala 1: 50.000, nas unidades Santo Eduardo e Itaocara. Estas unidades são descritas como biotita gnaisses com estrutura bandada ou laminada, geralmente migmatizados, contendo intercalações de quartzitos, anfibolitos, rochas calcissilicáticas e mármores dolomíticos, associadas com gnaisses diversos, incluindo anfibólio-biotita gnaisses, gnaisses com granada, gnaisses porfiroblásticos, gnaisses tonalíticos, migmatitos e biotita moscovita xistos. São descritas ainda associações freqüentes com rochas miloníticas, incluindo milonitos, milonito gnaisses, milonito xistos e blastomilonitos.

Como resultado destes trabalhos de cartografia geológica, foram definidos os Batólitos Serra das Araras e Rio Turvo (Barbosa \& Sad 1983, Ruiz et al. 1983), este último no domínio Juiz de Fora. Estes granitóides foram descritos como rochas foliadas, de aspecto gnaissóide, porfiróides, com foliação cataclástica conspícua, sendo como a presença de protomilonitos, milonito gnaisses e blastomilonitos. Posteriormente, eles foram denominados de leucogranitos aluminosos e classificados como granitos do tipo$\mathrm{S}$, cuja a origem foi atribuída à fusão parcial de metassedimentos e 
relacionada a uma tectônica colisional (Machado et al. 1989 , Machado \& Demange 1991). Eles foram ainda designados por Machado \& Demange (1984) de granitos do tipo-C (ou subtipoCS), da classificação de Didier et al. (1982), e granitos tipo Hercínico, segundo a classificação de Pitcher (1979).

Recentemente, no projeto carta geológica do estado do Rio de Janeiro em escala 1:400.000, efetuado pela CPRM (Silva et al. 2000), o Batólito Serra das Araras foi estendido para nordeste até o limite com o estado do Espírito Santo, sendo dividido em dois extensos batólitos: um contínuo com extensão de cerca de $200 \mathrm{Km}$ e outro descontínuo com extensão superior a $230 \mathrm{Km}$ (Fig. 1). Estes batólitos ocupam tanto a aba sul da estrutura-em-flor positiva do vale do rio Paraíba do Sul quanto a parte central desta estrutura.

No projeto da CPRM os granitos do tipo-S do DPS foram designados Suíte Serra das Araras (SSA) e correlacionados aos granitos Quebra Cangalha, Lagoinha, Serra das Abóboras, Serra da Concórdia, Serra das Frecheira e Parati-Mirim. A SSA é descrita como (granada) granito a duas micas do tipo-S, com granulação grossa, eqüigranular a porfirítico, com foliação transcorrente, rico em enclaves de paragnaisse. Inclui ainda fácies leucogranítica com sillimanita, granada, moscovita, biotita e turmalina preta como mineral acessório. Esta suíte, juntamente com as de Serra Selada, Varre-Saí e Santo Antônio de Pádua, foi considerada tardi-colisional e relacionada à movimentação das estruturas transcorrentes regionais. Esta suíte foi considerada tardi-colisional e sua colocação foi relacionada à movimentação das transcorrências regionais. Neste mesmo contexto, foram também englobados granitos do tipo-I pertencentes às Suítes Pedra Selada, Varre-Sai e Santo Antônio de Pádua, com esta última apresentando rochas da associação charnockítica (Silva \& Cunha 2000).

Estes autores descrevem ao longo do flanco sul da estrutura divergente do vale do Rio Paraíba do Sul, notadamente entre as regiões da Serra das Araras e Areal, uma faixa de rochas miloníticas e protomiloníticas com associação litológica heterogênea, constituída por granada-silimanita granitos porfiríticos com enclaves de rochas metassedimentares e anfibolitos, em associação com rochas paraderivadas migmatizadas e anfibólio-biotita ortognaisses cinzentos subordinados. Estes granitos são considerados litológica e estruturalmente correlatos ao batólito Serra das Araras definido por Barbosa \& Sad (1983), que aflora na extremidade sudoeste da faixa investigada (Silva et al. 2000, Silva e Cunha 2000, Cunha et al. 2000).

DOMÍNIO LITORÂNEO(DL) Neste domínio, os granitóides do tipo-S foram definidos recentemente nos trabalhos de cartografia geológica realizados pela CPRM em escala 1:400.000 (Silva et al. 2000). Trabalhos anteriores já assinalavam que muitas das unidades cartografadas como gnaisses kinzigítico deveriam corresponder na realidade a granitos do tipo-S gnaissificados (Machado 1997).

Nos trabalhos de cartografia geológica em escala 1:50.000, tais granitóides foram englobados em unidades de gnaisses diversos, tais como Santo Eduardo, São Fidélis, Desengano, Catalunha, Crubixais, Emesto Machado, Cassorotiba e Imbé (Batista et al. 1977, Ferrari et al. 1982). Estas unidades são descritas em geral como migmatitos homogêneos e heterogêneos ou diatexíticos e metatexíticos, não havendo nos trabalhos muitas vezes a preocupação em caracterizar a natureza do protólito. Ressalte-se, entretanto, que em vários destes trabalhos os granitos do tipo-S correspondem a rochas descritas como gnaisses porfiroblásticos, gnaisses granitóides, granitóides gnáissicos, leucogranitóides, gnaisses aluminosos, gnaisses kinzigíticos, leptinitos, gnaisses facoidais, cujos contatos são descritos frequientemente como de natureza transicional, difuso ou interdigitado (ver Ferrari et al. 1992, Reis et al. 1982).

No mapa geológico da CPRM em escala 1:400.000 foram discriminados no $\mathrm{DL}$ inúmeros maciços graníticos do tipo-S alongados e subconcordantes com a estruturação regional do cinturão. Estes maciços apresentam no segmento setentrional do Rio de Janeiro uma faixa mais expressiva com largura de cerca de $50 \mathrm{Km}$ e extensão que atinge $140 \mathrm{Km}$. Para sul, esta faixa torna-se mais estreita e mostra uma forte inflexão para $W$ na altura da cidade do Rio de Janeiro. Individualmente, os corpos graníticos possuem extensão entre 50 e $110 \mathrm{Km}$ e largura entre 3 e $6 \mathrm{Km}$. Na região de Niterói, esta largura pode atingir até $8 \mathrm{Km}$. Estas rochas foram designadas de Suítes Desengano e Rio de Janeiro e estão associadas como charnockitos. A primeira suíte é descrita como granito do tipo-S com granada, moscovita e biotita de granulação grossa, texturas granoblástica e porfirítica (augen) com forte foliação tangencial no estado sólido, contém abundantes xenólitos e restitos de paragnaisse, e apresenta como plútons correlatos os Granitos Santa Terezinha, Carapebus e Serra da Concórdia (Silva et al. 2000 , Silva \& Cunha 2000). A segunda suíte, descrita como granito do tipo-S contendo granada, moscovita e biotita de granulação grossa, texturas granoblástica e porfirítica (augen) com forte foliação transcorrente no estado sólido, engloba os Granitos Corcovado, Pão de Açucar e o Leucogranito gnáissico Cosme Velho (Fig. 1).

Os autores consideram estas suítes de granitos do tipo-S como relacionadas tectonicamente aos maciços charnockíticos ou de associação charnockítica (Bela Joana, Ilha da Madeira e Ilha da Marambaia) e vinculam os mesmos a um contexto tectônico tardicolisional e sua colocação foi relacionada à movimentação das transcorrências regionais

DISCUSSÃO Trabalhos recentes de integração regional sobre a geologia do Estado do Rio de Janeiro têm mostrado que o magmatismo peraluminoso neoproterozóico na região é mais importante do que se supunha anteriormente. Conforme já exposto neste trabalho, são registradas no Rio de Janeiro duas faixas expressivas de granitóides do tipo-S: uma no domínio Paraíba do Sul, que ocupa o segmento sul da estrutura-em-flor positiva de nome homônimo, e outro no domínio Litorâneo, que circunda o domínio Serra dos Órgãos pela sua porção sudeste.

Estes granitos do tipo-S contêm granada, sillimanita e, localmente, cordierita (Cunha et al. 2000) (Fig. 1). Muitos deles foram descritos anteriormente como gnaisses kinzigíticos, contendo enclaves de origem metassedimentar (calcissilicáticas, quartzitos, biotita gnaisses, anfibolitos) deformados, os quais conferem muitas vezes em escala de afloramento uma estrutura gnássica a estas rochas. Podem apresentar também uma intensa deformação no estado sólido, e recristalização em alta temperatura de minerais como feldspatos, sillimanita e quartzo. Este processo, além de promover o desenvolvimento de rochas com texturas miloníticas, incluindo microestruturas planares e fitadas, com ribbons de quartzo e microclina, pode ter contribuído para diferenciação de bandas micáceas e quartzo-feldspáticas.

A origem ígnea destas rochas é compatível com a descrição de contatos localmente intrusivos (Barbosa \& Sad 1983), relações de campo com os gnaisses regionais, texturas e dados geotermobarométricos existentes na literatura para o metamorfismo regional (Oliveira 1981, Rêgo 1989, Porcher 1994). Deste modo, os dados geológicos e geocronológicos disponíveis até então suge- 
rem a presença de intensa fusão parcial de metassedimentos associada à geração regional de granitos do tipo-S no Neoproterozóico, cujas idades devem situar-se ao redor de 590 a $580 \mathrm{Ma}$, ou até mais novas (Cordani et al. 1973, Figueiredo e Campos Neto 1993, Machado N. et al. 1996, Machado R. et al. 1996, Machado 1997, Tupinambá 1999).

Os modelos tectônicos regionais vinculam estas rochas à fase colisional brasiliana, com a geração do magma granítico sendo relacionada a fusão parcial de metassedimentos. $\mathrm{Na}$ concepção dos autores desses modelos, as idades disponíveis para os granitos (pico térmico) marcariam então a (s) fase(s) de colisão. Contudo, outros modelos são postulados para a geração destes granitos, sendo os mesmos discutidos a seguir e fundamentados em trabalhos recentes disponíveis na literatura. Inicialmente cabe salientar que o modelo aqui proposto considera a classificação tectônica apresentada recentemente para os granitos do tipo-S no estado do Rio de Janeiro (Silva et al. 2000, Silva \& Cunha 2000).

Vários trabalhos na literatura têm discutido a possibilidade de fusões crustais expressivas em períodos tardios ao de espessamento crustal, período este que pode ser muito variável, alcançando dezenas de milhões de anos (Figura 2). O incremento da fusão parcial pode também ser dado pela decompression melting devido a taxas suficientemente elevadas de denudação tectônica (Hollister 1993, Inger 1994). Dentre os parâmetros importantes para esta discussão, encontram-se as condições de pressão e temperatura esperadas para promover a fusão parcial (anatexia) extensiva de metapelitos. Estas condições são alcançadas quando as rochas regionais atingem condições de metamorfismo compatível com o grau alto.

Os trabalhos de petrologia experimental mostram que a temperatura de fusão do mínimo granítico para ambientes saturados em água é de cerca de $600^{\circ} \mathrm{C}$, com pressão de $10 \mathrm{~kb}$ (profundidades ao redor de $35 \mathrm{~km}$ ) (Wyllie 1977). Contudo, sob condições anidras, e com o mesmo valor de pressão, são necessárias temperaturas mais elevadas para promover uma fusão parcial extensiva, as quais devem atingir ao redor de 700 a $730^{\circ} \mathrm{C}$, sendo estes os valores considerados para a quebra da moscovita. Para a biotita, sob as mesmas condições de pressão, estes valores são ao redor de $800^{\circ} \mathrm{C}$ (Wyllie 1997) (fig.2). Estas reações são consideradas como marcadores do início da fusão parcial extensiva (Brown \& Fyfe 1970, Grant 1985) e ocorrem em ambientes não saturados em água, o que parece ser a situação mais comum da maioria dos ambientes crustais, sendo isto compatível com níveis de crosta média/inferior (Stevens \& Clemens 1993). Esta afirmação se contrapõe à clássica interpretação de LeFort (1986) e LeFort et al. (1987), que consideram a presença abundante de fluidos aquosos nas rochas do bloco inferior footwall em regiões associadas com tectônica de empurrão. Nesta condição tectônica, tais fluidos seriam capazes de promover a fusão generalizada de rochas relativamente mais quentes situadas no bloco superior hangingwall deste sistema de falhas, segundo o modelo de metamorfismo invertido ("ferrode-engomar") em ambiente de crosta média (Harris \& Massey 1994).

Barbarin (1996) divide os granitos peraluminosos em dois grupos: um contendo moscovita e outro, cordierita. A origem destes granitos é atribuída a fusão parcial de rochas crustais, envolvendo anatexia crustal sob condições 'úmidas' (primeiro grupo) ou 'secas' (segundo grupo). Os granitos com muscovita são gerados em ambientes tectônicos sob condições de crosta espessada e afetada por empurrões ou por grandes cisalhamento crustais, enquanto os granitos com cordierita são gerados em regiões subme- tidas a underplating ou injetadas por magmas do manto. Para alguns autores, o processo de geração de leucogranitos peraluminosos é inteiramente crustal e não envolve influxo de material do manto (Patiño Douce 1999).

England \& Thompson (1984, 1986), com base em um trabalho de modelagem matemática, apresentam um modelo de evolução térmica para cinturões dobrados envolvendo a existência de uma crosta continental duplicada. Neste modelo, o calor é transportado principalmente por condução, com o fluxo térmico sendo proveniente de duas fontes: do manto, com um valor constante, e da crosta, como produto de decaimento radioativo. Considerando-se esta situação tectônica (duplicação por empurrões), juntamente com os parâmetros físicos com significado geológico para a litosfera continental, as condições térmicas instaladas logo após a tectônica compressiva (duplicação) não favorecem a geração de fusões parciais expressivas (fig.2). As figuras em (A) e (B) mostram a modelagem instantânea de um empurrão ocorrido a $35 \mathrm{~km}$ de profundidade, onde são utilizados valores médios crustais de parâmetros como condutividade térmica, produção interna de calor por decaimento radioativo e fluxo térmico proveniente do manto. Considera-se que a erosão de $35 \mathrm{~km}$ de crosta ocorreu a 100 Ma., tendo iniciada a $20 \mathrm{Ma}$. após a duplicação crustal (England \& Thompson 1984). Nas figuras $2 \mathrm{C}$ e $2 \mathrm{D}$, a geoterma 0 (antes do espessamento) corresponde ao gradiente geotermal médio de áreas que foram sujeitas a eventos tectônicos em épocas anteriores a $250 \mathrm{Ma}$. Após um aquecimento isobárico de $30 \mathrm{Ma}$, as rochas são exumadas por uma tectônica extensional, por igual período. Além disso, o regime termal difere nos valores de produção interna de calor e da contribuição do manto ao fluxo térmico crustal (mod. de England \& Thompson 1986).

A condição tectônica acima promove a depressão das geotermas (Glazner \& Bartley 1985), de tal modo que quantidades significativas de fusões são esperadas durante a instalação de regimes térmicos transitórios (England \& Richardson 1977). A instalação destes regimes coincide com o período de relaxamento térmico e de soerguimento da pilha espessada. Assim, o aquecimento efetivo da pilha orogênica ocorre somente após o pico de pressão inicial. Nesta fase, as rochas metassedimentares alcançam mais facilmente temperaturas em condições compatíveis com a fácies anfibolito alto a granulito, sendo aí então o momento em que são geradas fusões graníticas mais expressivas.

No modelo apresentado por England \& Thompson (1986), a geração de fusões crustais sin-colisionais é fortemente dependente da presença de água no sistema e de um fluxo térmico relativamente elevado. Em alguns casos examinados pelos autores, as temperaturas na Moho são superiores a $1000^{\circ} \mathrm{C}$. Em outros casos, dependendo dos parâmetros utilizados, esta temperatura é alcançada em profundidades ao redor de $40 \mathrm{~km}$, o que é considerado um valor não realista para esta situação tectônica (Sandiford \& Powell 1991).

Assim, a disponibilidade de água livre no sistema e o conhecimento da estrutura termal da litosfera pré-colisional constituem-se em parâmetros importantes para a discussão da origem destas rochas durante a fase de espessamento principal. Para valores de temperatura na Moho em torno de $500^{\circ} \mathrm{C}$ (England \& Thompson 1984), ou próximos do valor requerido para gerar o liquidus granítico saturado em água (ao redor de $600^{\circ} \mathrm{C}$, com pressão de $10 \mathrm{~kb}$ - Harris et al. 1986), a geração extensiva de fusão crustal neste momento é fortemente dependente dos parâmetros acima.

Desta forma, mesmo que a origem destas rochas esteja vinculada ao espessamento crustal e perturbações térmicas impostas pela 

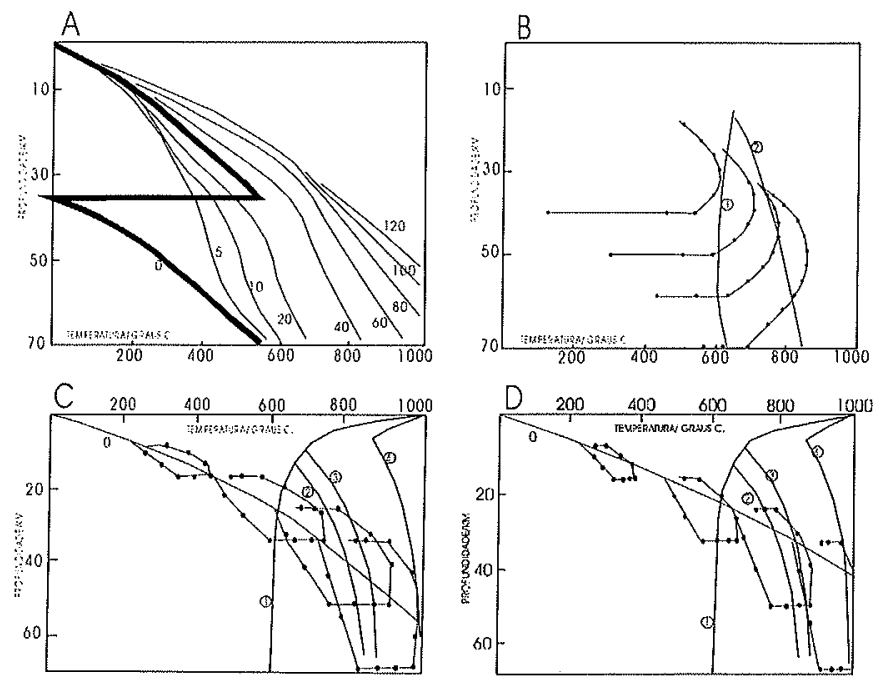

Figura 2 - Geração de granitos do tipo-S por fusão parcial de metassedimentos: (A) - Regimes térmicos transitórios impostos pelo relaxamento de uma perturbação térmica inicial gerada por empurrão a $35 \mathrm{~km}$ de profundidade; $(B)$ - Caminho P-T-t teórico para rochas a profundidades de 40,50,60 e $70 \mathrm{~km}, \mathrm{com}$ intervalos de $10 \mathrm{Ma} ; \mathrm{Em}(\mathrm{C})$ e (D), as profundidades são de 8.75 , 17.5, 26.25 e $35 \mathrm{~km}$, com a deformação sendo homogênea no intervalo de 30 M.a. Curvas de quebras de minerais por fusão: • com água em excesso; micas em metapelitos; f biotita e hornblenda em granodioritos e tonalitos; , hornblenda em anfibolitos.

tectônica compressiva no modelo colisional, é mais provável que elas tenham sido geradas após o ápice de pressão experimentado pelos seus protólitos. Por outro lado, mesmo assumindo o modelo de formação de granitos peraluminosos (tipo-S) no 'momento' da colisão, o modelo prevê também a geração de granitos posteriores, constituindo-se assim em um fenômeno essencialmente não simultâneo e transitório, cujo intervalo depende de vários fatores, tais como profundidade de soterramento experimentada pelas rochas (England \& Thompson 1984) e as próprias incertezas dos métodos geocronológicos utilizados (De Yoreo et al. 1989). Portanto, as idades obtidas nestas rochas devem ser consideradas, mais apropriadamente, como idades mínimas de um evento de espessamento crustal (colisão).

Para Sylvester (1998), os granitos fortemente peraluminosos são formados em vários tipos de orógenos como o resultado de processos pós-colisionais. Distingue os granitóides formados sob condições de alta pressão (espessamento crustal $=50 \mathrm{~km}$ ) e de alta temperatura (espessamento $=50 \mathrm{~km}$ ). Os primeiros evoluem em dois estágios: (i) estágio de aquecimento radiogênico in situ, sincolisional e, (ii) estágio de fusão por descompressão pós-colisional. Os últimos envolvem uma fonte de calor originada no manto, com a temperatura sendo igual ou superior a $875^{\circ} \mathrm{C}$. Segundo o autor, nos orógenos de alta temperatura, a anatexia crustal é produzida pela delaminação pós-colisional e ascensão da astenosfera quente.

Por outro lado, Barbarin (1999) considera que estes granitos são gerados no momento de 'clímax' da orogênese, com seus magmas sendo formados durante a fase tectônica compressiva. A sua co- locação ocorre somente em condições distensiva ao longo de zonas de cisalhamento ou sob condições de relaxamento local.

O modelo tectônico alternativo não discutido no presente trabalho para a geração desses granitos é o modelo que não envolve espessamento crustal extremo. Contudo, este modelo implica na existência de terrenos metamórficos de alta pressão, situação esta que não tem sido caracterizada nesse segmento do cinturão estudado. Neste caso, a ascensão de magmas passa a ser o principal mecanismo capaz de promover a transferência de calor (por advecção) para níveis superiores da crosta (DeYoreo et al. 1989 , Sandiford \& Powell 1991). Neste sentido, a interpretação temporal/tectônica dos granitos do tipo-S depende fortemente do entendimento do significado destes magmas.

No o modelo proposto por England \& Thompson (1984, 1986), deve se considerar também que o relaxamento térmico é posterior a deformação compressiva. Segundo o modelo, a fase de crescimento prógrado de minerais metamórficos (no sentido de aumento da temperatura) - modelo condutivo - deve ser mais nova do que o processo de deformação, com os granitos sendo formados amplamente nas fases tardi a pós-cinemáticas. Este modelo encontra dificuldades para ser aplicado nos granitóides estudados, pois os mesmos apresentam tramas frequientemente foliadas e/ou gnaissificadas. Para as rochas do Batólito Serra das Araras são descritas feições de deformação em estado sólido superpostas, juntamente com uma fase de crescimento mineral e migmatização (Dehler \& Machado 2001). Isto também ocorre provavelmente com os demais corpos de granitóides no domínio Litorâneo. Esta característica tectono-metamórfica pode ser interpretada de duas formas: (i) pela importância da tectônica de empurrão no encurtamento e duplicação crustal do CPS, com as estruturas presentes nos granitos tendo sido produzidas durante a fase de exumação do orógeno, sendo este modelo compatível com um regime transpressivo associado à convergência oblíqua de placas (Ebert \& Hasui 1998) e, (ii) ou pelo encurtamento de uma crosta já aquecida de forma anômala, o que corresponde à situação esperada em níveis de crosta média/inferior, onde é limitada a disponibilidade de fluídos aquosos, com a fusão parcial extensiva marcando temporalmente o 'momento' do espessamento crustal máximo.

Finalmente, cabe salientar que a interpretação tectônica aqui apresentada para os granitos do tipo-S (tardi-colisionais) do Rio de Janeiro, juntamente com os dados geocronológicos regionais de alto valor interpretativo disponíveis na literatura (Granito Rio Turvo, RJ: idade U/Pb, em monazita, de $579 \pm 2 \mathrm{Ma}$ - Valladares 1996; Granito Urucum, MG: idade U/Pb, em zircão, de $582 \pm 2 \mathrm{Ma}$ - Nalini 1997 e Nalini et al. 2000), não se ajustam na classificação tectônica de granitos proposta na Orogênese Rio Doce (Campos Neto \& Figueiredo 1995), pois as idades existentes situam-se no intervalo dos granitos pré-colisionais proposto pelos autores.

CONCLUSÕES Pela discussão acima conclui-se que, o uso de idades de granitos do tipo-S como marcadores de idade da tectônica sin-colisional em orógenos, não é de imediato, e que isto pode ser extensivo para orógenos com evolução estrutural semelhante, tanto do tipo alpino quanto Himalaiano. Neste sentido, informações adicionais são necessárias para melhor avaliação do tema. Tais informações incluem estrutura térmica da litosfera pré-colisional e disponibilidade de água no sistema.

Os dados geológicos disponíveis sobre granitos do tipo-S do Rio de Janeiro são mais compatíveis com ambiente tectônico do tipo tardi-colisional, sob condições de uma crosta espessada. Neste ambiente, os magmas graníticos são gerados após a fase de coli- 
são propriamente dita. Um forte argumento para isto é a estreita vinculação entre os granitóides e as zonas de cisalhamento dúcteis de alto ângulo regionais, principalmente as do vale do rio Paraíba do Sul, de forma análoga ao que tem sido descrito para os granitos peraluminosos com muscovita no Maciço Central Francês (Barbarin 1996 e 1999). Além disso, os contatos dos maciços estudados são tectônicos e balizados por estruturas de alto e baixo ângulo.

O modelo alternativo aqui apresentado para a geração dos granitos do tipo-S é compatível com os modelos tectônicos existentes na literatura, principalmente os baseados na petrologia experimental, onde a geração de volume expressivo de material granítico se relaciona à fusão parcial (anatexia) de crosta duplicada tectonicamente em ambiente colisional. Neste caso, as fusões graníticas são produzidas extensivamente, quando são atingidos os valores de temperatura de quebra da moscovita $\left(\sim 700^{\circ} \mathrm{C}\right) \mathrm{e}$ biotita $\left(\sim 800^{\circ} \mathrm{C}\right)$, sob condições hidratadas (pressões $\sim 10 \mathrm{~Kb}$ ) (Wyllie 1977, Grant 1985). Para granitos fortemente peraluminosos são consideradas temperaturas superiores a $875^{\circ}$ (orógenos de alta temperatura) ou inferiores (orógenos de alta pressão) (Sylvester 1998). A anatexia crustal também é o processo considerado para a geração dos granitos peraluminosos com muscovita (Barbarin 1996). Alguns autores desvinculam a adição de material do manto para formação destes granitos (Patiño Douce 1999).

Um outro esquema ainda não suficientemente explorado nos modelos tectônicos aplicados para granitóides similares aos aqui estudados, e que pode explicar a deformação no estado sólido presente nestas rochas, é o da superposição de um regime tectônico associado com a exumação do orógeno. Este caso não exclui a superposição de deformações tectônicas mais jovens.

Embora dados adicionais sejam ainda necessários para melhor subsidiar a discussão sobre a alternativa de modelo tectônico aqui proposto para os granitos do tipo-S no Rio de Janeiro, as informações geológicas aqui apresentadas são compatíveis com os trabalhos existentes na literatura. A existência de granitos do tipo-S no segmento norte do cinturão Paraíba do Sul (Granito Urucum, MG, e Granito Colatina, ES), considerados anteriormente como sin-colisionais (Nalini 1997), com características geológicas similares aquelas descritas no presente trabalho, sugere igual- mente uma interpretação como granitos tardi-colisionais.

Em síntese, se for considerado apenas o modelo de espessamento crustal por empurrões durante a colisão continental, conclui-se que os grandes batólitos graníticos do tipo-S do Rio de Janeiro foram gerados também após a fase de máximo espessamento crustal (tardi-colisional), como resultado da fusão parcial (anatexia) de rochas predominantemente metassedimentares. A colocação deste magmatismo teria sido controlada por zonas de cisalhamento dúcteis de alto e baixo ângulo. Neste caso, as deformações presentes nessas rochas podem ser atribuídas em parte ao regime tectônico responsável pela exumação da faixa e, em parte, pela reativação destas estruturas oconida ao final do Ciclo Brasiliano. No primeiro caso, as relações geológicas e estruturais observadas entre as diferentes fases de intrusões graníticas sugerem a coexistência entre deformações em estado sólido e em estado magmático, enquanto no segundo, as deformações presentes nos granitos deveriam ser essencialmente em estado sólido.

Conclui-se pela discussão acima que, no segmento estudado, tanto a classificação tectônica dos granitos relacionados à Orogênese Rio Doce quanto a sua própria duração precisam ser revistos, pois o acervo de dados geocronológicos de alta precisão até então disponível sugere que o intervalo de 590 a $570 \mathrm{Ma}$, considerado pelos autores como intervalo do magmatismo précolisional, corresponde, na realidade, a um intervalo relacionado com a colocação de granitos tardi-colisionais, onde o processo dominante na região foi o de uma anatexia crustal extensiva. Além disso, a discussão deste trabalho sugere que a definição de estágios evolutivos de orogêneses com base apenas em estudos de ambiência tectônica de granitos é muito questionável, conforme também tem sido discutido por outros autores na literatura.

Agradecimentos Os autores agradecem à CPRM - Serviço Geológico do Brasil, pelo apoio durante e após as atividades de campo, à FAPESP (Proc. 98/00912-8), pelo suporte financeiro que permitiu a realização de parte dos trabalhos de campo, ao $\mathrm{CNPq}$ (Proc. 300423/82-9, de R. Machado), pela concessão de uma bolsa de Produtividade em Pesquisa. Aos revisores da RBG pelas sugestões ao manuscrito.

\section{Referências}

Almeida J. C. H. 2000. Zonas de cisalhamento dúcteis de alto grau do Médio Vale do Rio Paraíba do Sul. Instituto de Geociências e Ciências Exatas, Universidade Estadual Paulista, Rio Claro, Tese de Doutoramento, 190p.

Barbarin B. 1996. Genesis of the two main types of peraluminous granitoids. Geology, 24 (4):295-298.

Barbarin B. 1996. A review of the relationships between granitoid types, their origins and their geodynamic enviromenments. Lithos 46:605-626.

Barbosa A. L. M. \& Sad J. H. G. 1980. Projeto Carta Geológica do Estado do Rio de Janeiro, Folhas Anta, Duas Barras, Teresópolis e Nova Friburgo. Niterói, GEOSOL-DRM, 316 p. (Relatório Final).

Barbosa A. L. M. \& Sad J. H. G. 1981. Projeto Carta Geológica do Estado do Rio de Janeiro, Folhas Cava, Miguel Pereira, Paraíba do Sul e Três Rios. Niterói, GEOSOL-DRM, 295 p. (Relatório Final).
Barbosa A. L. M. \& Sad J. H. G. 1983. Projeto Carta Geológica do Estado do Rio de Janeiro, Folhas Piraí, Paracambi, ItaguaíMarambaia. Niterói, GEOSOL-DRM, 382p. (Relatório Final).

Barbosa A.L.M. \& Sad J.H.G. 1985. Batólito Granítico da Serra dos Orgãos, Estado do Rio de Janeiro, Brasil: Contribuição a Geologia e Petrologia. Boletim Especial do Núcleo de Minas Gerais, pg. 49-61.

Barbosa A. L. M., Lima E.C.V.S., Sad J. H. G., Alves M.R., Baltazar O.O F., 1981. Projeto Carta Geológica do Estado do Rio de Janeiro, Geologia das Folhas Varre-Sai, Eugenópolis, Itaperuna e Miracema. Niterói, GEOSOL-DRM, 262p. (Relatório Final).

Brandalise L. A., Ribeiro J. H., Ferrari P. G. 1976. Projeto Vale do Paraíba do Sul. Rio de Janeiro, DNPM/CPRM, 411 p. (Relatório Final).

Brown G.C. \& Fyfe W.S. 1970. The production of granitic melt during ultrametamorphism. Contr. Mineral. Petrol., 28:310-318.

Campos Neto M.C. \& Figueiredo M.C.H. 1995. The Rio Doce orogeny, 
Southeastern Brazil. J. Sou. Am. Ear. Sci., 8:143-162.

Castro H.O., Queiroz M.A., Barbosa A.L.M., Sad G.J.H. 1984. Geologia das folhas Rio Preto, Valença, Barra do Piraí e Vassouras. In: SBG, Congr. Bras. Geol., 33, Rio de Janeiro, Anais, 5:2346-2354.

Castro H.O., Rocha R.L.S., Sperling E.V., Baltazar O.F. 1984b. Geologia das folhas Mangaratiba, Ilha Grande, Cunhambebe, Angra dos Reis, Rio Mambucaba/Campos de Cunha, Picinguaba e Juatinga RJ. In: SBG, Congr. Bras. De Geol., 33, Rio de Janeiro, Anais 5:2355-2367.

Chappel B.W. \& White A.J.R. 1974. Two contrasting granite types. Pacific Geology, 8:173-174.

Cordani U.G., Delhal J., Ledent D. 1973. Orogénèses superposées dans le Pré-Cambrian du Brésil Sud-Oriental (États de Rio de Janeiro et de Minas Gerais). Rev. Bras. Geoc, 3:1-22.

Cunha H.C., Dehler N.M., Vieira V.S., Raposo F.O., Perillo I.A., Silva P.C.S. 2000. Projeto Compilação Geológica do Estado do Rio de Janeiro. Rio de Janeiro, CPRM/DRM (Mapa Geológico).

Dehler N. M. \& Silva P. C. S. 2000 . Projeto de compilação geológica da Folha Volta Redonda (escala 1:250.000). São Paulo, CPRM, 16p. (Nota Explicativa).

Delhal J., Ledent D., Cordani U.G. 1969. Ages U/Pb, Rb/Sr et K/Ar de formations métamorphiques et granitiques du Sud-Est du Brésil (États de Rio de Janeiro et de Minas Gerais). Ann. Soc. Géol. Belgique, 92:271-283.

DeYoreo J.J., Lux D.R., Guidotti C.V. 1989. The role of crustal anatexis and magma migration in the thermal evolution of regions of thickened continental crust. In: J.S. Daly, R.A. Cliff, B.W.D. Yardley (Eds.) Evolution of Metamorphic Belts. Geol. Soc., London, Special Publication 43:187-202.

Ebert H. 1955. Pesquisa na parte sudeste de Minas Gerais e Polígono das Secas. Relatório Anual do Diretor, DNPM/ DGM:79-89.

Ebert H. 1968. Ocorrências de fácies granulíticas no sul de Minas Gerais e em áreas adjacentes em dependência da estrutura orogênica: hipóteses sobre sua origem. An. Acad. Bras. Ciênc., 40 (Suplemento):215-229.

Ebert H. D. \& Hasui Y. 1998. Transpressional tectonics and strain partitioning during oblique colision between three plates in the precambrian of south-east Brazil. In: R. E. Holdsworth, R. A. Strachan, J. F. Dewey (eds.) Continental transpressional and transtensional tectonics. Geol. Soc., London, Special Publication, 135:231-252

England P.C. \& Richardson S.W. 1977. The influence of erosion upon the mineral facies of rocks from different metamorphic environments. J. Geol. Soc. London, 134:201-213.

England P.C. \& Thompson A.B. 1984. Pressure-temperature-time paths of regional metamorphism I: heat transfer during the evolution of tegions of thickened continental crust. J. Petrol., 25:894-928.

England P.C. \& Thompson A.B. 1986. Some thermal and tectonic models for crustal melting in continental collision zones. In: M.P. Coward \& A.C. Ries (eds.) Collision Tectonics, Geol. Soc., London, Special Publication 19:83-94.

Figueiredo M.C.H. \& Campos Neto M.C. 1993. Geochemistry of the Rio Doce magmatic arc, Southeastern Brazil. Anais Acad. Bras. Ciênc., 65 (Suplemento 1):63-81.

Fonseca M.J.G. 1998. Mapa geológico do Estado do Rio de Janeiro, escala 1:400.000. Rio de Janeiro, DNPM/MME, 141p. (Texto Explicativo)

Glazner A.F. \& Bartley J.M. 1985. Evolution of lithospheric strength after thrusting. Geology, 13:42-45.

Grant J.A. 1985. Phase equilibria in partial melting of pelitic rocks. In: J. R. Ashworth (ed.) Migmatites. New York, Blackie, 86-144
Harris N.B.W., Pearce J.A., Tindle A.G. 1986. Geochemical characteristics of collision-zone magmatism. In: M.P. Coward \& A.C. Ries (eds.) Collision Tectonics, Geological Society, London, Special Publication 19:67-81.

Harris N. \& Massey J. 1994. Decompression and anatexis of Himalayan metapelites. Tectonics, 13:1537-1546.

Hasui Y., Carneiro C.D.R., Coimbra A.M. 1975. The Ribeira folded belt. Rev. Bras. Geociências, 5:257-266.

Hasui Y. \& Oliveira M.A.F. 1984. A Província Mantiqueira - Setor Central. In: F.F.M. Almeida \& Y. Hasui (Coord.) O PréCambriano do Brasil, São Paulo, Edgard Blücher.

Heilbron M. 1993. Evolução Tectônico-metamórfica da seção Bom Jardim de Minas (MG)-Barra do Piraí (RJ). Setor central da Faixa Ribeira. Inst. de Geociências, Universidade de São Paulo, São Paulo, Tese de Doutoramento, 268p.

Heilbron M. 1995. O segmento central da Faixa Ribeira: síntese geológica e ensaio de evolução geotectônica. Departamento de Geologia e Geofísica, Universidade Estadual do Rio de Janeiro, Rio de Janeiro, Tese de Livre Docência, 110p.

Heilbron M., Valeriano C.M., Valladares C.S., Machado N. 1995. A orogênese brasiliana no segmento central da Faixa Ribeira, Brasil. Rev. Bras. Geoc., 25:249-266.

Heilbron M., Machado R., Figueiredo M.C.H. 1997. Lithogeochemistry of Paleoproterozoic orthogranulites from the Rio Preto (MG)Vassouras (RJ) region, central Ribeira Belt, SE Brazil. Rev. Bras. Geoc., 27:83-98.

Hobbs B.E., Means W.D., Williams P. F. 1976. An outline of structural geology. New York, John Wiley \& Sons: $571 \mathrm{p}$.

Hollister L.S. 1993. The role of melt in the uplift and exhumation of orogenic belts. Chem. Geol., 108:31-48.

Inger S. 1994. Magmagenesis associated with extension in orogenic belts: examples from the Himalaya and Tibet. Tectonophysics, 238:183-197.

Junho M.C.B., Weber-Difenbach K., Wiedemann C., Penha H.M. 1987 Major and minor elements geochemistry of Pedra Branca, Frades and Nova Friburgo granitic complexes, Ribeira Mobile Belt, RJ, Brazil. Rev. Bras. Geoc., 17:507-511.

Junho M.C.B. 1993. Granitóides brasilianos da região central do Estado do Rio de Janeiro - geoquímica preliminar. An. Acad. Bras. Ciênc., 65:161-179.

Junho, M. C. B. 1998. Rochas granitóides do estado do Rio de Janeiro. In: M.J.G. Fonseca (Coord.). Mapa geológico do Estado do Rio de Janeiro, escala 1:400.000. Rio de Janeiro, DNPM/MME, 141p. (Texto Explicativo).

Lamego A.R. 1938. Escarpas do Rio de Janeiro. Bol. Serviço de Geologia e Mineração, DNPM, 93:1-72.

Lamego A.R. 1948. Folha Rio de Janeiro. Bol. Serviço de Geologia e Mineração, DNPM, 126: 16p.

LeFort P. 1986. Metamorphism and magmatism during the Himalayan collision. In: M.P. Coward \& A.C. Ries (eds.) Collision Tectonics, Geol. Soc., London, Special Publication 19:159-172.

LeFort P., Cuney M., Daniel C., France-Lanord C., Sheppard S.M.F, Upreti B.N., Vidal P. 1987. Crustal generation of the Himalaian leucogranites. In: H.K. Gupta (ed.) Deep seated processes in collision zones. Tectonophysics, 134:39-57.

Machado Filho L., Ribeiro M.W., Gonzales S.R., Schemini C.A., Santo Neto A., Palmeira R.C.B., Pires J.L., Teixeira W., Castro H.E. 1983. Projeto RADAMBRASIL, Folhas Rio de Janeiro/Vitória (SF. 23/24) (Levantamento de Recursos Naturais): 29-304. (volume 32)

Machado N. \& Gauthier G. 1996. Determination of 207Pb/206Pb ages 
on zircons and monazite by laser-ablation ICPMS and aplication to sedimentary provenance and metamorphism in southeastern Brazil. Geoch. Cosmoch. Acta, 60:5063-5073.

Machado N., Valladares C., Heilbron M., Valeriano C. 1996. U/Pb geochronology of the central Ribeira belt: implications for the evolution of brasiliano orogeny. Prec. Res., 79:347-361.

Machado R. 1984. Evolução Geológica, Análise Estrutural e Metamórfica da Região de Vassouras e Paracambi, Porção Ocidental do Estado do Rio de Janeiro. Inst. de Geociências, Universidade de São Paulo, São Paulo, Tese de Doutoramento, 196p.

Machado R. 1997. Litogeoquímica e tectônica dos granitóides neoproterozóicos do Cinturão Paraíba do Sul no Estado do Rio de Janeiro. Inst. de Geociências, Universidade de São Paulo, São Paulo, Tese de Livre-Docência, 215p.

Machado R. \& Pellogia A.U.G. 1987. Mapa de distribuição das rochas granitóides do Estado do Rio de Janeiro: uma avaliação preliminar das informações disponíveis. In: SBG/Núcleo São Paulo, Simp. Reg. Geol., 4, Rio Claro, Atas, 1:93-96.

Machado R. \& Demange M. 1990. Reinterpretação estrutural e tectônica da região a Leste da Baía da Guanabara e a definição do Batólito de Araruama. In: SBG, Congr. Bras. de Geol., 36, Natal, Anais, 6:2744-2754

Machado R. \& Demange M. 1992. Granitogênese brasiliana no Estado do Rio de Janeiro: Caracterização geoquímica, modelo tectônico e considerações geológicas sobre o embasamento e a cobertura do cinturão Ribeira na região. In: SBG, Congr. Bras. de Geol., 37, São Paulo, Boletim de Resumos Expandidos, 1:379-380

Machado R. \& Demange M. 1994 a. O batólito cordilherano Serra dos Órgãos: um exemplo de arco magmático brasiliano com assinatura toleiítica no Sistema de Cisalhamento Paraíba do Sul, no Estado do Rio de Janeiro. In: SBG, Congr. Bras. Geol., 38, Camboriú, Anais, 1:114-115

Machado R. \& Demange M. 1994 b. Classificação estrutural e tectônica dos granitóides neoproterozóicos do Cinturão Paraíba do Sul no Estado do Rio de Janeiro. Boletim do IG-USP, 25:81-96

Machado R. \& Demange M. 1998. Caracterização geoquímica e tectônica dos granitóides pré-colisionais neoproterozóicos do Cinturão Paraíba do Sul no Estado do Rio de Janeiro. In: H. Conceição (ed.) Contribuição ao estudo dos granitos e rochas correlatas, SBG/ Núcleo Bahia-Sergipe, Publicação Especial, 5:21-39

Matos G.M.M., Ferrari P.G., Cavalcante J.C. 1980. Projeto faixa calcárea Cordeiro-Cantagalo. Belo Horizonte, CPRM, 620p. (Relatório Final)

Nalini Júnior H. A. 1997. Caracterization des suites magmatiques néoproterozoiques de la région de Conselheiro Pena et Galiléia (Minas Gerais, Brésil): étude géochimique et structurale des suites Galiléia et Urucum et leur relation avec les pegmatites à éléments rares associées. École des Mines de Saint-Etienne et École des Mines de Paris, Thèse de doctorat, 237p.

Nalini H. A..Jr., Bilal, E., Paquette, J.L., Pin, C. and Machado, R. 2000. Géochronologie U-Pb et géochimie isotopique $\mathrm{Sr}-\mathrm{Nd}$ des granitö̈des néoproterozoïques des suites Galiléia et Urucum, vallée du Rio Doce, Sud-Est du Brésil.. C. R. Acad. Sci. Paris, Sciences de la Terra et des Planètes, 331:459-466.

Oliveira M. A. F. 1980. Petrologia das rochas granuliticas da Faixa Paraíba do Sul, Estados do Rio de Janeiro e Minas Gerais. Inst. de Geociências e Ciências Exatas, Universidade Estadual Paulista, Tese de Livre-Docência, 116p.

Patiño Douce, AA.E. 1999. What do esperiments tell us about the relative contributions of crust and mantle to the origen of granitic magmas? In: A. Castro, C. Fernández, \& J. L. Vigneresse (eds.) Understanding Granites. Integrating New and Classical
Technique. Geological Society, London, Special Publication 168:55-75.

Penha H.M., Ferrari A.L., Ribeiro A., Amador E.S., Pentagna F.P., Junho M.C.B., Brenner T.L. 1979. Projeto Carta Geológica do Estado do Rio de Janeiro, Folha Petrópolis. Rio de Janeiro, DRM/ UFRJ, 194p. (Relatório Final).

Penha H. M., Ferrari A.L., Junho M.C.B., Souza S.L.A., Brenner T.L. 1981. Projeto Folha Itaipava. Rio de Janeiro, DRM/UFRJ, 177p. (Relatório Final).

Porto Jr. R., Sanchez B., Meighan I.G., Fallick A.E. 1996. Geologia, geoquímica e geocronologia do batólito Serra dos Órgãos. In: SBG, Congr. Bras. Geol, 38., Salvador, Anais, 6:445-448

Ragati D., Tupinambá M., Heilbron M., Paschoal Duarte B., Valladares C.S. 1999. New Sm/Nd isotopic data from Pre-1.8 Ga basement rocks of Central Ribeira Belt, S.E. Brazil. In: SEGEMAR, Simp. Sud. de Geol. Isot., 2, Córdoba, Actas, pp. 346-348.

Rêgo I.T.S.F. 1989. Petrologia e geoquímica da unidade charnockítica Bela Joana, região de São Fidélis, RJ. Inst.de Geociências, Universidade de São Paulo, São Paulo, Tese de Doutoramento, 348p.

Reis A.P., Castro H.O., Dalcomo M.T., Ferrari A.L., Mel F., Neves L.F.L., Vaz M.A.A., Silva V.P., Nassar W.M. 1982 a. Geologia das Folhas Morro do Côco, Barra Seca, Itabapoama, Travessão, São João da Barra, Campos, Muçurepe, Lagoa Feia e Farol de São Tomé, RJ. In: SBG, Congr. Bras. Geol., 32, Salvador, Anais, 1:7585.

Reis A.P., Rocha R.L.S., Barbosa A.L.M., Lima E.C.V., Sad J.H., Alves M.R., Baltazar O.F. 1982b. Geologia das Folhas Varre-Sai, Eugenópolis, Itaperuna e Miracema. RJ. In: SBG, Congr. Bras. de Geol., 32., Salvador, Anais, 1:86-93.

Reis A.P., Castro H.O., Puget A.J.F., Barbosa A.L.M., Lima E.C.V., Ribeiro A.C., Pinto C.P., Dutra J.E.B., Sad J.H.G. 1982c. Geologia das Folhas Três Rios, Paraíba do Sul, Miguel Pereira e CavaRJ. In: SBG, Congr. Bras. Geol., 32., Salvador, Anais, 1:94-102.

Rosier G.F. 1957. A geologia da Serra do Mar entre os picos da Maria Comprida e do Desengano. DNPM/DGM, Boletim 166p.

Rosier G.F. 1965. Pesquisas geológicas na parte oriental do Estado do Rio de Janeiro. DNPM/DGM, Boletim, 222p.

Ruiz M., Costa A., Raposo F.O. 1983. Projeto Carta geológica do Estado do Rio de Janeiro: folhas Santa Rita do Jacutinga, Volta Redonda, Resende, Barra Mansa, Liberdade, Bananal, Passa Quatro, Agulhas Negras, São José do Barreiro, Nossa Senhora do Amparo. Niterói, CPRM/DRM, 7 vol. (Relatório Final).

Sandiford M. \& Powell R. 1991. Some remarks on high-temperaturelow-pressure metamorphism in convergent orogens. J. Metam. Geol., 9:333-340.

Silva L.C. \& Cunha H.C. (coord.) 2000. Projeto Cpmpilação Geológica do Estado do Rio de Janeiro. CPRM/DRM, Rio de Janeiro, 88 pp. (Relatório de Geologia)

Silva L.C., Santos, R.A, Delgado, I.M., Cunha, H.C. (Coord.) 2000. Mapa Geológico do Estado do Rio de Janeiro em escala 1:400.000. CPRM/DRM, Rio de Janeiro.

Sylvester P.J. 1998. Post-collisional strongly peraluminous granites. Lithos 45:29-44.

Stevens G. \& Clemens J.D. 1993. Fluid-absent melting and the roles of fluids in the lithosphere: a slanted summary? Chem. Geol., 108:117.

Trouw R.A.J., Heilbron M., Ribeiro A., Paciullo F.V.P., Valeriano C.M., Almeida J.C.H., Tupinambá M., Andreis R. 2000. The central segment of the Ribeira Belt. In: U.G. Cordani, E.J. Milani, A. Thomaz Filho, D.A. Campos (eds.) Tectonic Evolution of South America, Rio de Janeiro, 2000: 287-310. 
Tupinambá M. 1999. Evolução tectônica e magmática da Faixa Ribeira na região serrana do estado do Rio de Janeiro. Inst. de Geociências, Universidade de São Paulo, São Paulo, Tese de Doutoramento, 221p.

Valladares C.S. 1996. Evolução geológica do complexo Paraiba do Sul, no segmento central da Faixa Ribeira, com base em estudos de geoquímica e geocronologia $U-P b$. Inst. de Geociências, Universidade de São Paulo, São Paulo, Tese de Doutoramento, 147p.

Valladares C.S., Heilbron M., Machado N., Valeriano C.M. 1997. Provenance of central Ribeira Belt metassediments using ${ }^{207} \mathrm{~Pb} /$ ${ }^{206} \mathrm{~Pb}$ ages on zircon by laser-ablation ICPMS. In: CPGeo-USP/ Simp. Sul. de Geol. Isot., 1, Campos do Jordão, Abstracts: 323325.

Valladares C.S., Machado N., Heilbron M., Tupinambá M., Duarte B.P., Gauthier G., Noronha M. 1999. Ages of detrital zircon from central Ribeira Belt (Brazil) using laser-ablation-ICPMS. In: SEGEMAR/ Simp. Sud. de Geol. Isot., 2, Córdoba, Actas, pp.: 145-147.

Wiedemann C.M. 1993. The evolution of the Paleozoic, late- to postcollisional magmatic arc of the coastal mobile belt, in the state of Espiríto Santo, eastern Brazil. An. Acad. Bras. Ciênc. 65 (Supl. 1):163-181.

Wyllie P.J. 1977. Crustal anatexis: an experimental review. Tectonophysics, 43:41-71.

Manuscrito A-1281

Recebido em 17 de novembro de 2101

Revisão dos autores em 15 de novembro de 2002

Revisão aceita em 20 de novembro de 2002 